Chirurgia (2020) 115: 432-440

No. 4, July - August

Copyright@ Celsius

http://dx.doi.org/10.21614/chirurgia.115.4.432

\title{
How to Write a Clinical Paper: Basics, Tips, Traps - Part II
}

\author{
Florin Botea ${ }^{1,2}$, Irinel Popescu ${ }^{1,2^{*}}$ \\ ${ }^{1}$ Center of General Surgery and Liver Transplantation, Fundeni Clinical Institute, Bucharest, Romania \\ ${ }^{2}$ Faculty of Medicine, University "Titu Maiorescu", Bucharest, Romania
}

*Corresponding author:

Professor Irinel Popescu

Center of General Surgery and Liver

Transplantation

Fundeni Clinical Institute

Soseaua Fundeni 258, Bucharest,

Romania, 022328

E-mail: irinel.popescu220@gmail.com

\section{Rezumat}

Cum se redactează o lucrare științifică: principii, sfaturi, capcane - partea a II-a

Unul dintre obiectivele principale ale clinicienilor este îmbunătățirea constantă a asistenței medicale, prin transferul de expertiză şi prin implementarea de inovații. Prin urmare, activitatea publicistică este extrem de importantă. Mai mult, această activitate este poate la fel de importantă şi pentru dezvoltarea carierei academice. Toată lumea medicală, de la studenți la medici seniori, avansează publicând lucrări şi obținând citarea acestora. Învățarea modului optim de a redacta o lucrare ştiințifică şi de a o trimite către revistele de specialitate ar trebui să fie un obiectiv pentru toți studenții, rezidenții, clinicienii şi cercetătorii. Scopul lucrării de față, publicată în trei părți, este de a ajuta pe cei interesați în scrierea şi publicarea în mod eficient a lucrărilor lor ştiințifice; partea a II-a se refera la procesul de redactare a unei lucrări ştiințifice.

Cuvinte cheie: lucrare ştiințifică, articol clinic, abilități redacționale

\section{Abstract}

One of the main goals of clinicians is to constantly improve the healthcare by spreading their expertise and by introducing innovations in medical science. Therefore, publishing is of utmost importance. Moreover, publishing helps authors in developing their academic carrier. Learning how to properly write and submit a manuscript should be a goal for all medical students, residents, clinicians and researchers. Everyone, from students to senior 
physicians and surgeons, advance in their carrier by publishing papers and by getting their work cited by others. The aim of this paper, published in three parts, is to enable the readers to write and publish their work effectively; the current part is addressing the actual writing process of a clinical paper.

Key words: clinical paper, scientific article, writing skills

Once the preparation for writing the paper is made (1), the main sections of the manuscript may be written.

\section{Article Structure}

The sections of a complete paper are the followings:

- Cover letter

- Title

- Authors

- Abstract

- Keywords

- Main text (IMRAD) $(2 ; 3 ; 4 ; 5)$.

- Introduction

- Methods

- Results

- Discussion/Conclusions

- Acknowledgements

- References

- Figures and tables.

- Supplementary materials

\section{Tips}

For best results, write your manuscript in a different order:

- Authorship

- Methods

- Figures and tables

- Results

- Discussion

- Conclusion

- Introduction

- Abstract

- Title

- Keywords

- Acknowledgements

- References

- Supplementary materials

- Cover letter

\section{Writing the Body of the Paper}

\section{Authorship}

Authorship can be a rather difficult matter. It is important to establish the authorship early in the writing process, which should be comprehensive (6). Fulfilling the criteria for authorship, as reviewed by the International Committee of Medical Journal Editors, requires all authors to have substantial contributions to the following (some journals will require a description of each author's contributions) (7):

- conception and design of the work;

- collection, analysis, and interpretation of the generated data;

- writing the manuscript;

- reviewing and revising it for intellectual content;

- approving the final version of the manuscript for publication.

The senior author should establish the authors and the order in which their names are listed. If no senior author is involved, the co-authors should come to an agreement on this matter. The first author is the one that contributes the most to the development of project, to the data collection, to the analysis process, and/or the writing of the manuscript. If more than one author meets the criteria for first author, this should be clearly stated in the manuscript. If different from the first author, the senior author typically takes the responsibility for mentoring the first author. The corresponding author is responsible for communicating with the editor and reviewers of the journal where the manuscript is submitted to, as well as with the readers that raise questions or comments after publication. 
The senior and corresponding authors are often the same person. All authors should agree on the order of middle authors, which may be established based on contribution (8).

Any individual that contributed to the work but does not meet the authorship criteria, could and should be acknowledged at the end of the article (7). Contributing with cases, or providing funds or materials, generally is not enough to warrant authorship.

\section{Institutions}

The affiliations should be listed in the title page only. Do not provide the affiliations or any information within the main text that can contribute to the identification of authors; this is important to avoid bias by the reviewers. After a successful review (acceptance of the manuscript), the name of the institutions and affiliations may be added in the text, if considered useful by the authors.

\section{Figures and Tables}

Your tables and figures should be build first, as they are the essence of your results, allowing you to review and verify your findings and to continue the workflow of writing.

Illustrations, including figures (schematics, algorithms, formulas, drawings, pictures, charts) and tables, are the most efficient way to depict your results. Your data are the driving force of the paper, so your illustrations are of utmost importance. Remember that "a figure is worth a thousand words". Reviewers and readers often look first at the illustrations and may not further read the entire paper if the illustrations do not catch their attention. Therefore, you should be particularly careful to include in your manuscript clear and informative illustrations.

You must choose the type of illustration to use for depicting your data. Generally, schematics, drawings and algorithms are used for describing the methods, while tables, charts and pictures are used to depict the actual experimental results, the comparisons with those of previous studies or with calculated/theoretical values.
Table 1. Proper table design

\begin{tabular}{lcc}
\hline Topography of LIs & No of pts & $\%$ \\
\hline Right hemiliver & 27 & 60,0 \\
\hline Left hemiliver & 10 & 22,2 \\
\hline Bilobar & 7 & 15,6 \\
\hline Segment 1 alone & 1 & 2,2 \\
\hline
\end{tabular}

Tips

- Evaluate your findings based on the tables and figures; if your results are inconsistent, you should reconsider your study at this point, saving a lot of time otherwise wasted in writing the next section of the paper.

- Pay attention to the appearance of your tables and figures, which should be simple and clear.

- Data should be easy to interpret (include clear symbols and data sets).

- Use different line styles to clarify the meaning.

- Pay attention to the use of decimals, lines, etc.

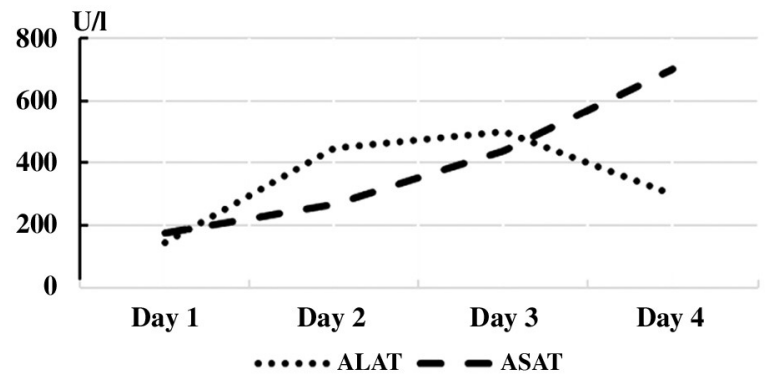

Figure 1. Proper graphic lines

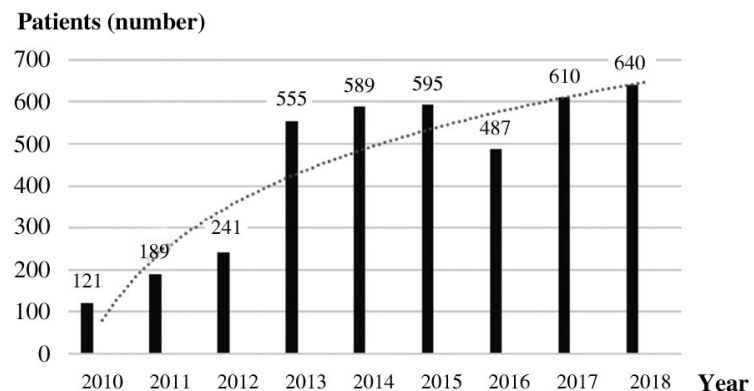

Figure 2. Proper graphic histograms (data is organized, trend line is present) 
- For photographs, it is recommended to include a scale marker or bar.

- Color should only be used when necessary.

- For charts, appropriately choose the axis label size.

- For charts, use properly the lines and histograms. Lines joining data should be used for time series or consecutive samples data. You must use histograms when there is no connection between samples.

- Captions must be self-explanatory, without the need to read the entire manuscript.

- Captions should not include to many details (that should be included in the main text).

\section{Traps}

- Illustrations should not duplicate the information described elsewhere in the manuscript.

- Avoid fonts too small for the journal, or they may be illegible to readers.

- Avoid crowded tables.

- Never use tables in the paper that are too long and boring or thar contains excessive data; if necessary, you may include them as supplementary material.

- Avoid crowded plots, using only three or four data sets per figure;

- Pay attention to colors and other visual effects, as they are charged separately, with expensive fees. However, this does not apply to online journals. For many journals, you can submit duplicate figures: one in color for the online version, and another in black and white for the hardcopy version.

\section{Patients and Methods}

Based on your notes, it should not be difficult to describe the study design. However, your notes and/or experimental protocols should be carefully written in advance in order to avoid complications in writing this section. Your most important goal at this point is to be very clear by providing enough details and references, thus enabling other researchers to evaluate and replicate your work. Furthermore, cohesion and fluency are vital in this section.

This section can be split into several specific parts that describe (9):

- The population (patients) or materials the patients or materials of the study must be fully described: e.g., when patients are involved in the study, their demographic characteristics and all information relevant to the study must be detailed.

- the setting, location

- the study design / methodology:

- planned sample size (including methods to establish it);

- procedure and instrumentation: the surgical technique, radiological technique, drugs used (preparation, dose, route of administration, timing, etc.), etc;

- other methods: clinical trials (randomized), experiments, surveys, systematic reviews, meta-analysis, reviews, case reports, etc;

- the statistical methods used (including confidence levels, etc.);

- the outcome (variables) - define the primary and secondary endpoints;

- any methods to guarantee validity, reliability, and repeatability (controls);

- any assumptions;

- the weaknesses of the methodology.

- Ethical considerations.

There are some generic guidelines for main study designs, such as:

- CONSORT: parallel randomized trials;

- STROBE: observational studies in epidemiology;

- STARD: diagnostic accuracy studies;

- COREQ: qualitative research;

- SQUIRE: quality improvement studies;

- COGS: clinical practice guidelines PRISMA: systematic reviews;

- MOOSE: systematic reviews of observational studies in epidemiology;

- Case reports;

- More specialized designs (often extending the generic guidance):

- CONSORT for cluster trials;

- CONSORT non-inferiority trials; 
- CONSORT for pragmatic trials.

Tips

- All the methods used must be thoroughly described.

- List the methods in the logical order in which you did the research, and maintain that order in the Results section.

- Be detailed but related only to the unpublished procedures.

- Identify the equipment and materials used; all manufacturer's details must be mentioned.

- Use the past tense.

Traps

- Avoid adding comments, results, and discussion.

- Don't include details on any previously published procedures, that should be cited in the References or described in the Supporting Materials section.

\section{Results}

Report results of the investigations described in the Methods section (in the same order) using text, tables, graphics (figures, schematics, algorithms, and formulas) and statistics. Present only the main results of your work, that are essential for discussion. Be as brief and clear as possible. For the data, decide on a logical order that expresses a clear and selfexplanatory story. Also report on adverse effects, as well as benefits, if relevant. Outline any ways in which the study did not follow the established methodology.

A typical structure and chronology include:

- Description of study participants (if relevant, separately for important subgroups).

- Presentation of answers to the main questions (starting with primary outcomes, then secondary outcomes, and any other analyses).

Summarizing the data, generalizing from the data, and highlighting scientific facts are all highly interpretive processes. You must interpret data for the reader (10). Feel free to include less relevant data in the Supplementary Materials.

Tips

- Use sub-headings to keep results of the same level together (it is easier to review and read).

- Number these sub-sections for the convenience of internal cross-referencing, but always consider the publisher's Guide for Authors.

- Use figures and tables to summarize data - pay special attention to presentation of data and results.

- Show the statistical results.

- Justify the selection of your methods.

- Verify that your methods were consistent.

- Define the limitations of your methods.

- Use the past tense.

Traps

- Don't attempt to exclude data in order to save it for a later paper, as you may not be able to strengthen your conclusion.

- Don't exclude any result of your work (intentionally or unintentionally), even the 'disappointing' ones.

- Don't include to many data; for excessive data you can use Supplementary materials.

- Don't let the data speak for themselves; explain them clearly.

- Don't repeat data in tables, figures and text.

- Don't use graphics to depict data that can easily be summarized in text.

- Don't include irrelevant information.

- Don't include references in this section (you are presenting your results, so you cannot refer to others here). When you refer to others when discussing your results, it should be included in the Discussion section.

\section{Statistical rules}

- Indicate the statistical tests used, mentioning all relevant parameters: e.g., mean and standard deviation (SD): $57 \%$ $( \pm 7)$; median and inter-percentile range: 7 years (3.5 to 9.5 years). 
- Give numerator and denominators with percentages: $25 \%(25 / 100)$.

- Use means and standard deviations to describe normally distributed data.

- Use medians and inter-percentile ranges to describe skewed data.

- For numbers, use two significant digits unless more precision is necessary (12.23, not 12.228452364276).

- Never use percentages for very small samples e.g., "one out of four" should not be replaced by $25 \%$.

- Report the specific P values: $\mathrm{p}=0.0014$, rather than $\mathrm{p}<0.05$.

- The word "significant" should only be used when referring to "statistically significant differences".

\section{Discussion}

This is the most important section of the manuscript, where you can impress the readers with your data. For many, writing a Discussion section is as frightening as starting a paper. Most of the fear comes from the variation in the section. Since every paper has its unique results and findings, the Discussion section varies in structure and length. However, some general principles of writing this section still exist (11).

The purpose of the Discussion section is to place your findings in the research context and to explain the meaning and the importance of the findings, in the most simple and effective manner, without appearing arrogant (12).

Many manuscripts are rejected because this section is poorly crafted.

The recommended steps for constructing the Discussions are the followings $(12,13)$ :

1. Study's major findings:

o State briefly the study's major findings.

o Explain the meaning and importance of your finding.

o How the findings relate to the original question or objectives outlined in the Introduction section (do the data support your hypothesis?).

o If your results were unexpected, explain why. o Assessment of study strengths and weaknesses (were your methods successful?).

o Consider alternative explanations of the findings.

2. Research context:

o Compare and contrast your findings with published results (how did your results relate to those of others?)

o Comment any discrepancies resulted in your comparison.

o State the limitations, weaknesses, and assumptions of your study in comparison to other.

o Consideration of clinical and scientific implications.

3. Closing the paper:

o Summarize the answers to the research questions.

o Indicate the importance of the work by stating applications, recommendations, and implications.

o If relevant, suggestions for future research to answer the questions raised by your results.

One of the main challenges for many authors is the opening paragraph of the Discussion section. The best option is to start with your major findings that respond to your study question included in Introduction. The most common starting phrases are "Our findings demonstrate..." or "In this study, we have shown that..." or "Our results suggest..." (11).

However, reminding the readers about the research question or even providing a brief context and then stating the answer would make more sense in certain situation. This is particularly true when several research questions and/or when authors present several findings. After summarizing the main findings, the authors should present the importance of these findings (11).

The structure of the first two steps is almost a mirror reflection of the one in the Introduction. In the Introduction, you zoom in from general to specific and from the background to your research question; in the Discussion section, you zoom out from the summary of your findings to the research 
context (11).

In the first step (main findings of the study) presenting the findings briefly and clearly, and analyzing their importance is decisive (11). One of the most frequent mistakes of the apprentice writer is to assume that the importance of his findings is self-explanatory and self-understood. Even if the importance is clear to you, it may not be obvious to your reader. Probably it is the easiest section to write, but the toughest to get it right.

Another useful strategy is to be proactive in the first step by predicting and commenting on the alternative explanations of the results. Addressing potential doubts will save you from painful comments about the wrong interpretation of your results and will present you as a thoughtful and considerate researcher. Moreover, the evaluation of the alternative explanations might help you create a logical step to the next step of the discussion section: the research context (step 2) (11).

In the second step, you should discuss the your findings in comparison to other studies. The goal of the research context is to show how your findings integrate (or not) into the overall perspective of the current published data and how you contribute to the existing knowledge on the topic. This is also the place to discuss any discrepancies and unexpected findings that may otherwise alter the general impression on your paper (11). Moreover, outlining the scope of your research by showing the limitations, weaknesses, and assumptions is essential and adds modesty.

In the last step of Discussion (Closing the paper), make sure that you do not end your paper with the problems that override your findings. Try to suggest feasible explanations and solutions (11).

Your writing should clear, precise and comprehensive, expressing confidence and authority. Use the active voice and the firstperson pronouns. These tools are the best to convince your readers of your ideas and messages (11).

For most journals, the Conclusions are included in the Discussion section. If your submission does not require a separate Conclusion section, adding a paragraph about the "take-home message" is mandatory. This should be a general statement on your answer to the research question and its scientific implications, practical application, or advice (11).

Tips

- Make the Discussion correspond to the Results.

- Maintain the flow of ideas connected, following a logical pattern.

- Keep the ideas well supported by your results and/or by the ones already published.

- Explain what is new in your work without exaggerating.

- Use quantitative descriptions.

- Speculations are allowed, but only based on facts and not imagination.

- Compare the published data with your results.

- Use the present tense.

Traps

- Do not mix discussion with results, introduction and conclusion.

- Do not reiterate the results.

- Do not exaggerate your findings, do not make overstatements not sustained by your methods or results. Example: "This novel treatment will hugely increase the number of healed patients"

- Do not use inappropriate assessments on your own accomplishments.

- Do not introduce new terms or ideas not mentioned previously in your paper

- Do not exclude papers in contrast with your findings; on the contrary, challenge them and prove that you are right or better.

- Do not forget to discuss the limitations of your study.

\section{Conclusions}

In the rare situations when separated from Discussion, describe briefly and clearly:

- How your work improves the field. 
- Indicate the use of your work.

- State any ongoing experiments.

- Propose future experiments based on your work.

- Use the present tense.

Traps

- Avoid diminishing your negative results.

- Avoid making statements unsupported by scientific facts.

- Avoid repeating sentences from other sections.

- Avoid exaggerating your findings.

\section{Introduction}

The Introduction must deliver a context for your manuscript and convince the readers that your work would be useful for the studied topic. Editors want to see that you have provided a perspective consistent with the scope of the journal. You need to introduce the main publications on which your work is based, citing few original and important papers, including up to date reviews. The Introduction allows your readers to evaluate their interest in your paper and plays a significant role in the paper review process.

Clearly address the following:

- Short review of the paper's topic (outline of what was achieved up to date).

- Weaknesses of the existing reports.

- Aim of the study (the problem you are trying to solve).

- Scope of the study (the solution to this problem, that you are analyzing in the paper)

Build the Introductions (11) in 3 steps:

1. Background information about your topic - establish the research territory and highlight the importance of your topic:

o Show that the research area is important, interesting, but problematic in some way(s), citing key primary published papers;

o Introduce and review the issues of previous research.

2. Find a niche (outline the scope of your research and enter the scientific dialogue): o Indicate a gap in the previous research or extend previous knowledge in some way.

3. Occupy the niche (briefly explain your aims and rationale and highlight your paper's significance):

o Outline purposes or state the nature of your research.

o List research questions or hypotheses.

o State the approaches used for your study.

o Announce expected findings.

o State the value of your research.

In the Introduction, you must respond to the following questions:

- Which is the issue that needs a solution?

- What is the current knowledge about this issue?

- Are there any existing solutions to this issue?

- Which are the limitations or gaps in the current knowledge about this issue?

- How does your findings fill these limitations or gaps?

Tips

- Be short, limited to maximum two paragraphs (consult the Guide for authors).

- The introduction must be organized from the global to the point of view, guiding the readers to your objectives.

- You should start as broad as possible, summarizing the significant general knowledge on the research area, and focus progressively to your study.

- Hypothesis and objectives must be clearly remarked at the end of the introduction.

- Use only highly relevant sources.

- Use keywords from your title.

- Use signal phrases, e.g.: "The objective of this study is...", "The purpose of this study was...", "We investigated..."

- Use key verbs, e.g.: "This study describes / investigates / presents / assesses,"

- Use the present tense whenever possible.

- Remember that most editors and reviewers appreciate the quality by reading the first paragraph of Introduction 
(along with the title and the abstract).

Traps

- Avoid long introductions (put readers off).

- Avoid incomplete introductions (common error).

- Do not forget that you need to give the whole picture at first.

- Do not make this section a history lesson.

- Do not use misjudgments on your own accomplishments.

- Do not blend introduction with the other sections of your manuscript.

- Do not forget to define all terms.

- Do not cite papers irrelevant to the work,

- Do not exclude diverging works or studies of your competitors.

After finishing the Introduction, the body of the paper is finalized. Prior to submitting, the manuscript needs to be completed with the last sections, in the recommended order: Abstract, Title, Keywords, Acknowledgements, References, Supplementary materials and Cover letter.

\section{Conflict of Interest}

The authors declare no conflicts of interests.

\section{References}

1. Botea F, Popescu I. How to Write a Clinical Paper: Basics, Tips, Traps. Part I. Chirurgia (Bucur). 2020. In press.

2. Baker PN. How to write your first paper. Obstetrics, Gynaecology \& Reproductive Medicine. 2012 3//;22(3):81-2.

3. Cetin S, Hackam DJ. An approach to the writing of a scientific manuscript. J Surg Res. 2005;128(2):165-7.

4. Vintzileos AM, Ananth CV. How to write and publish an original research article. American Journal of Obstetrics and Gynecology. 2010 4//:202(4):344.e1-.e6.

5. Singer AJ, Hollander JE. How to Write a Manuscript. The Journal of Emergency Medicine. 2009 1//;36(1):89-93.

6. Koniaris LG, Coombs MI, Meslin EM, Zimmers TA. Protecting ideas: ethical and legal considerations when a grant's principal investigator changes. Sci Eng Ethics. 2016;22(4):1051-61.

7. UNiform requirements for manuscripts submitted to biomedical journals. Jama. 1997;277(11):927-34.

8. Liang TW, Feliciano DV, Koniaris LG. A surgery trainee's guide to writing a manuscript. Am J Surg. 2017 Sep;214(3):558-563.

9. Bajammal S, Dahm P, Scarpero HM, Orovan W, Bhandari M. How to use an article about therapy. J Urol 2008;180:1904-11.

10. Penrose AM, Katz SB. Writing in the sci- ences: Exploring conventions of scientific discourse. New York: St. Martin's Press; 1998.

11. Kallestinova E D. How to Write Your First Research Paper. Yale J Biol Med. 2011;84(3):181-190.

12. Swales JM, Feak CB. Academic Writing for Graduate Students. 2nd edition. Ann Arbor: University of Michigan Press; 2004.

13. Hess DR. How to Write an Effective Discus- sion. Respiratory Care. 2004;29(10):1238-41. 